\title{
Processing data on sea bottom structure obtained by means of the parametric sounding
}

\author{
Eugeniusz Kozaczka1,2), Prof. \\ Grażyna Grelowska1), Prof. \\ Sławomir Kozaczka'1), M.Sc. \\ Wojciech Szymczak'), M.Sc. \\ 1) Polish Naval Academy, Poland \\ 2) Gdansk University of Technology, Poland
}

\begin{abstract}
The aim of the paper is to analyze data obtained during sounding the Gdansk Bay sea bed by means of the parametric echo-sounder. The accuracy of the sea bottom structure investigation needs correct configuration of research equipment and proper calibration of peripheral devices (GPS, heading sensor, MRU-Z motion sensor and navigation instruments which provide necessary data to bathymetrical measurement system, enabling its work with full capability. The parametric sub-bottom profiler delivers two types of data which include different information: envelope and pure echo signal sampled without processing. The first is used to present echograms in real time and the second one is stored during sounding and the obtained data can be analyzed by using post-processing software. Differences in the results are presented and discussed. And, are described also criteria taken into account during determination of the measurement areas and selection of different configurations of the software according to the information to be obtained from trials. Complementary information can be achieved from processing the data by means of the procedures offered by Matlab software, which allows for a clear 3D presentation of the results. The consideration are illustrated by echograms taken in the natural conditions.
\end{abstract}

Keywords: sea bottom acoustic; sub-bottom profiler; sea bed structure

\section{INTRODUCTION}

A bathymetrical measurement system fitted with SES-2000 sub-bottom profiler was installed on a small survey vessel of $10.5 \mathrm{~m}$ in length. Parametric echo-sounder antenna was installed on starboard and EM3002 multibeam transducer - on port, $100 \mathrm{~cm}$ below water surface on special mounting arms. Additional navigation devices were tested in different localizations and finally mounted in the places best suited to their functions. GPS was installed in the vessel's centre line, close to deck to minimize speed and position errors. MRU-Z motion sensor was fitted near the vessel's gravity centre. Application of the SES-2000 Standard - parametric sub-bottom profiler makes it possible to observe structure of the upper layers of seabed. Parametric sources used in studying the seabed allow - as a result of the minimum impact of two acoustic beams radiated into the water in the same area - to generate low frequency waves (of a few $\mathrm{kHz}$ only) of the geometric properties similar to the characteristics of the so-called primary waves. This allows for observation of stratification of the seabed with relatively high accuracy. In addition, the use of the equipment intended for the so-called electronic stabilization, in this particular case the MRU-Z system, allows to eliminate the sounding beam movement associated with the movement of the antenna. After mounting the sounding devices, measurements were done to define lever arms and compensation parameters for each of the bathymetrical units. Signals from GPS and heading and motion sensor are distributed through multiplying modules to different devices. Trials on Gdansk Bay with calibrated instruments on small measurement vessel were made and interesting solutions connected with processing and sounding were quoted. At the beginning of this article, is presented and discussed information obtained during trials on the water tank $30 \mathrm{~m}$ long, $3 \mathrm{~m}$ wide and $1.5 \mathrm{~m}$ deep, owned by Gdansk University of Technology.

\section{METHOD OF DATA PROCESSING}

The analysis of data obtained during trials is preceded by information on characteristic parameters of antenna (directivity, sounding pulses) and methods of data processing prior to echogram visualization. Sounding pulse (of $4 \mathrm{kHz}$ frequency and two-pulse length) measured at $4 \mathrm{~m}$ distance from transducer (the near measurement point II marked in Fig. 2), is plotted in Fig. 1. The calculated depth resolution of such configuration amounts to $37.5 \mathrm{~cm}$. 


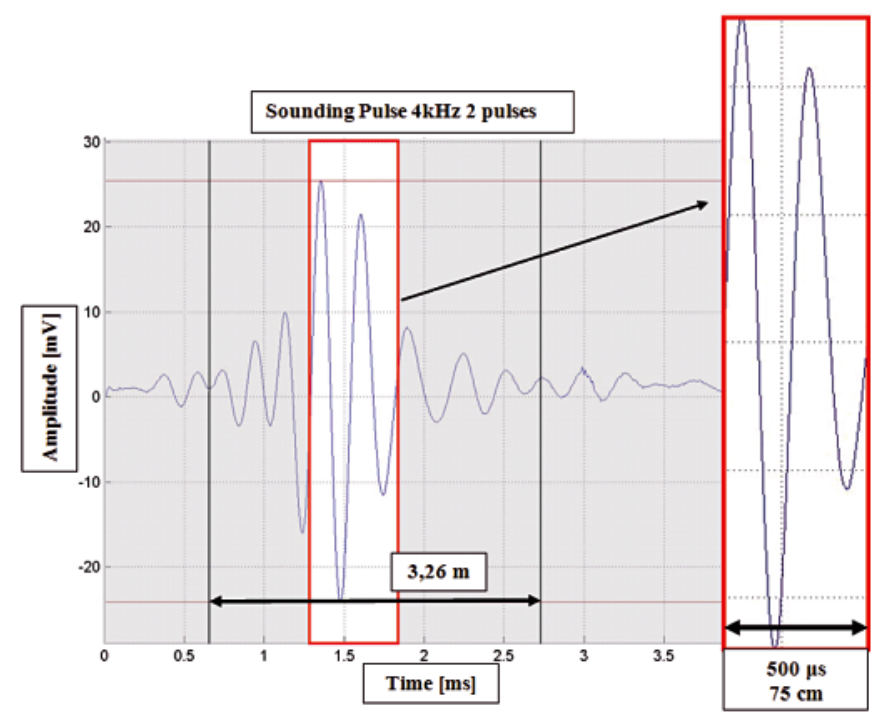

Fig. 1. Sounding pulse measured at $4 \mathrm{~m}$ distance from transducer

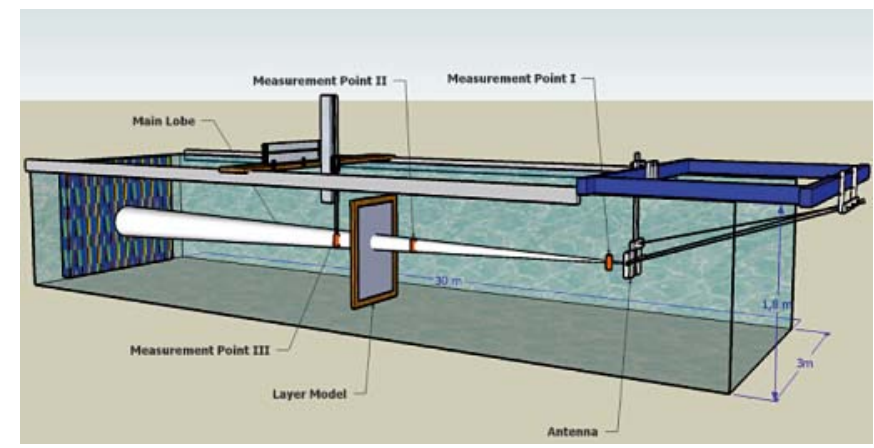

Fig. 2. Schematic view of the water tank

The data visualization method are presented on the example of sounding the concrete wall. Plots shown in the figures below were recorded with the use of Tektronix oscilloscope connected to analogue output of the echo-sounder, which provides a filtered and amplified signal just before sending it to analogue-digital converter (such signal is shown in Fig. 3). Fig. 4 illustrates the envelope calculated from pure echo signal.

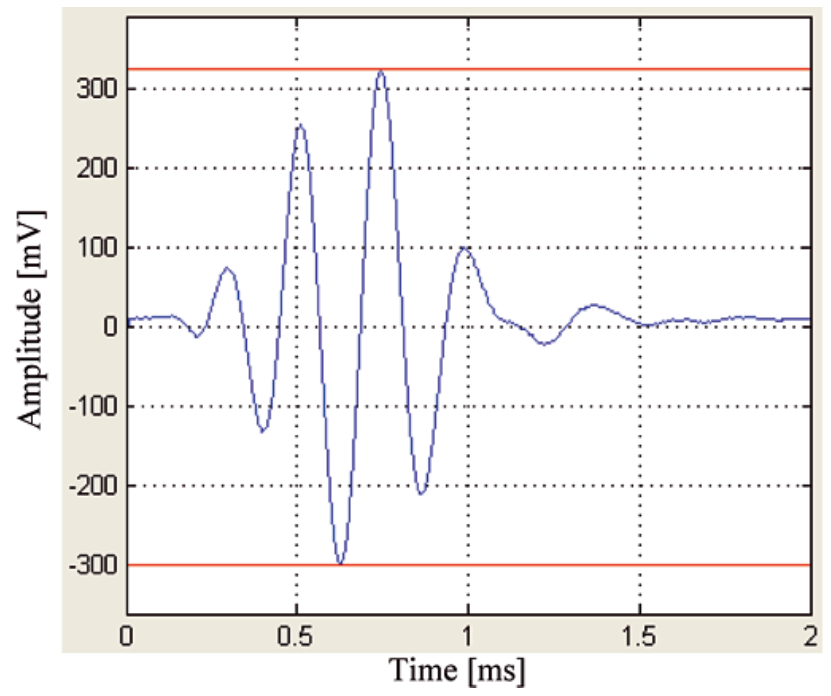

Fig. 3. Echo of sounding pulse

The measured signal length is $1.5 \mathrm{~m}$, but not all its fragments should take part in visualization, that is shown in Fig. 5 where the gray flat area is the threshold, i.e. LF Min Level for small echoes and noise. Changing this value can strongly

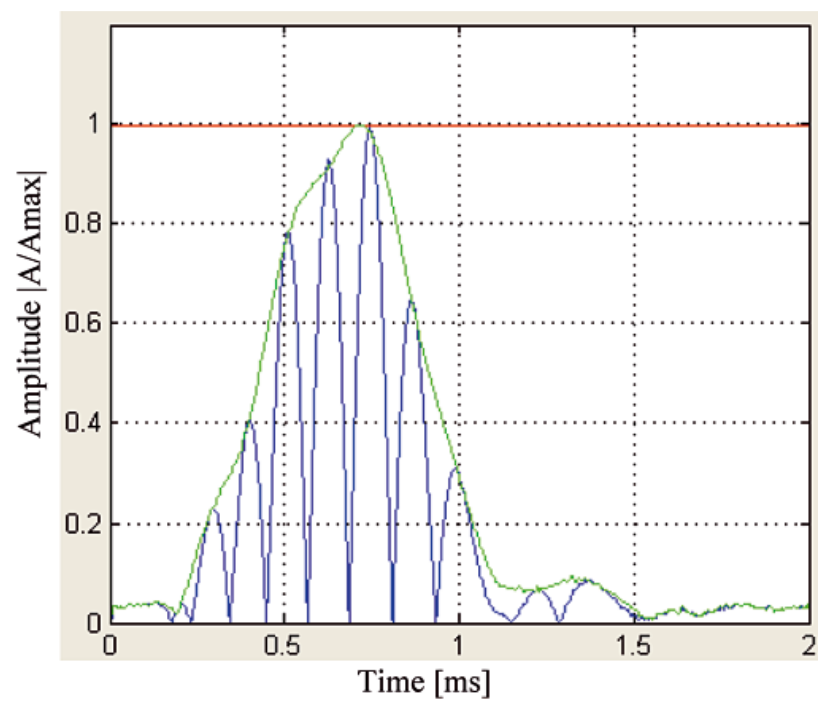

Fig. 4. Envelope of received pulse

influence visualization model and help examination of received information. The typical echogram which describes result of the sounding with all cut-off filters set to minimum values, is shown in Fig. 6.

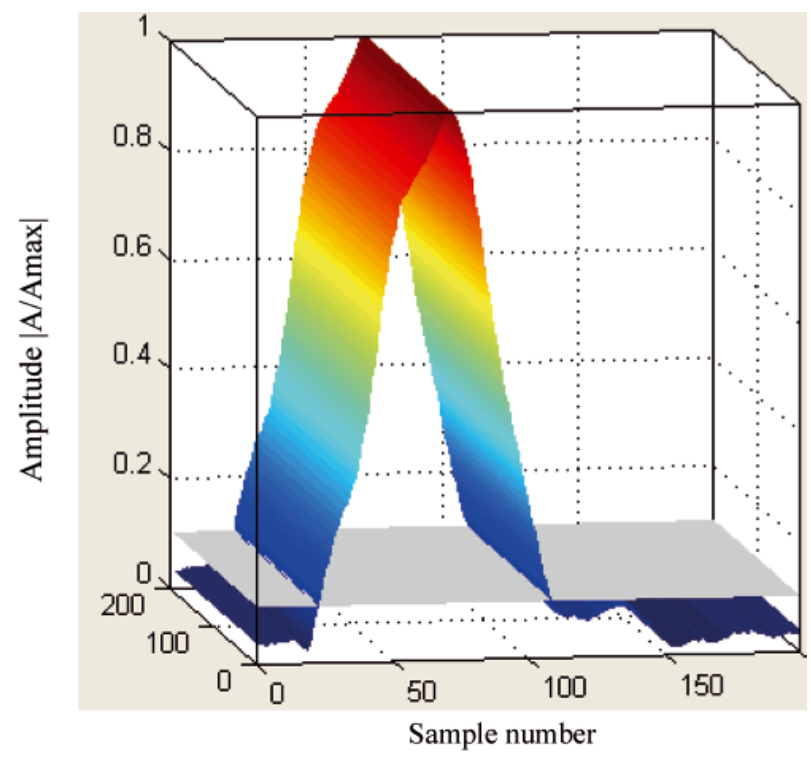

Fig. 5. 3D visualization performed by using the Matlab software

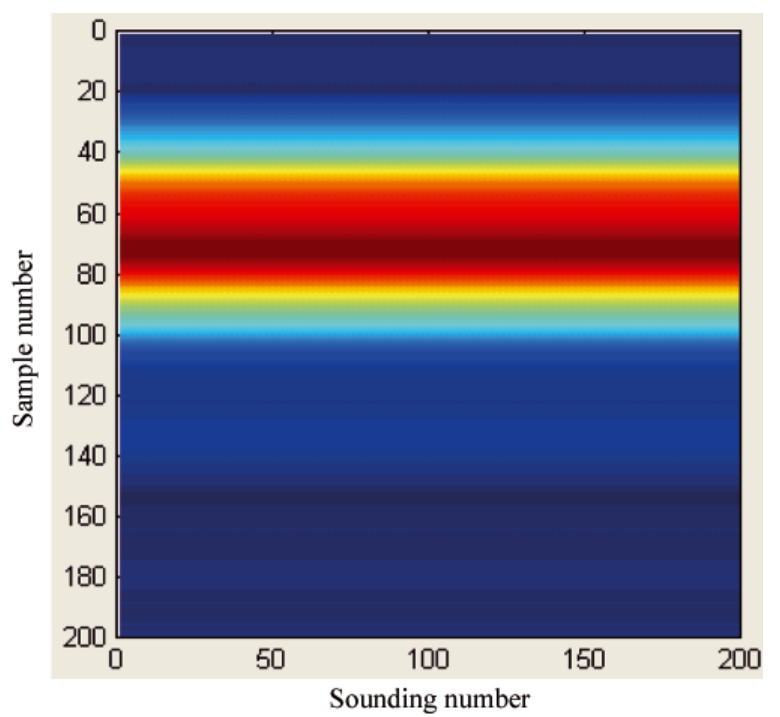

Fig. 6. 2D echogram received from the Matlab software 
The data received from the stationary measurements in $30 \mathrm{~m}$ water tank, were used during analyzing the results from the trials at Gdansk Bay. It was important to set depth resolution for different sounding pulses depending on their frequency $(4,6,8,10,12-15 \mathrm{kHz})$ and number of pulses which represent number of cycles. Increasing number of pulses increases energy of transmitted signal (better signal to noise ratio) but decreases the depth resolution:

$$
\text { Depth_resolution }=\mathrm{t}^{*} \mathrm{c} / 2
$$

Where:

$\mathrm{t}$ - time,

c - sound velocity in water

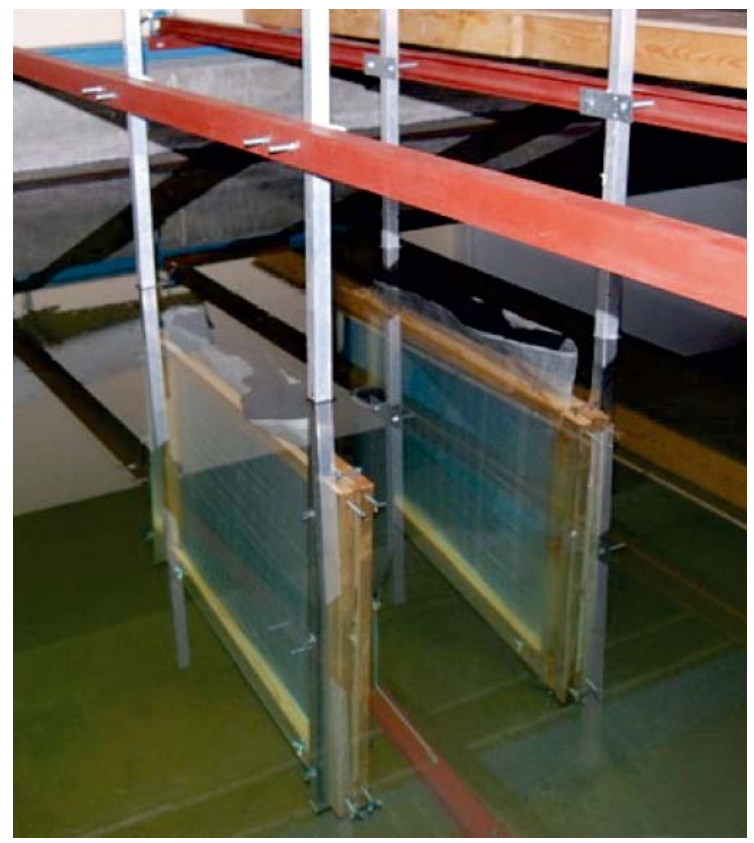

Fig. 7. Measurement layers with SES data file possible to be processed after recording

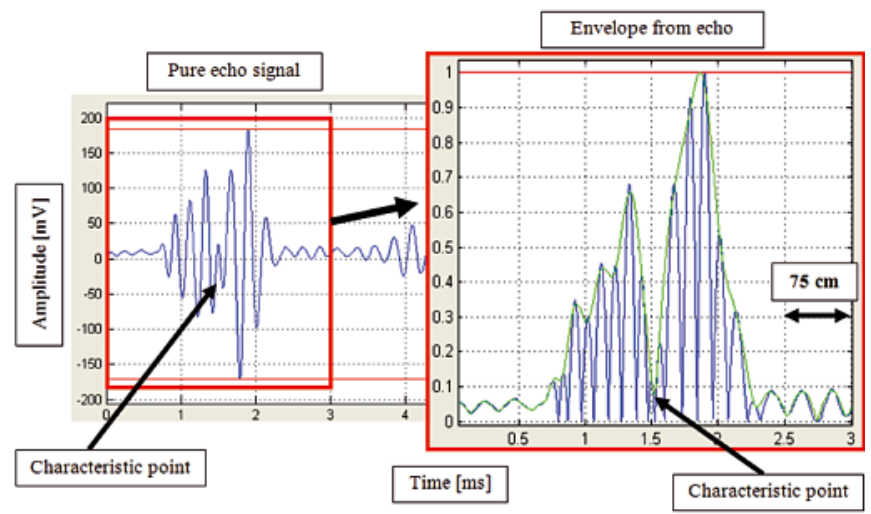

Fig. 8. Echo and envelope of received signal

The result obtained from sounding two artificial sediment layers is shown in Fig. 8. The two artificial sediment layers were arranged in the configuration shown in Fig. 7, where their mutual distance was $35 \mathrm{~cm}$. Looking at the result, one can notice a characteristic point in which a jump in the envelope (shown on echogram as free space) is formed during calculating the envelope. The free space length depends on threshold level and type of visualization method, but the length is correlated with free space between frames.

\section{DATA RECEIVED FROM SOUNDING Comparison of pure signal and lower resolution envelope}

Data from the sounding at Gdansk Bay where penetration depth of sediments reached 40 meters (the starting point is set at $50 \mathrm{~m}$ below sea surface) are presented in Fig. $9.4 \mathrm{kHz}$ frequency and 2 pulses length signal is used. The two following charts describe comparison of the data:

- SES data - contain 480 samples used to draw echograms in real time.

- RAW data - contain 5120 samples which are stored in parallel.

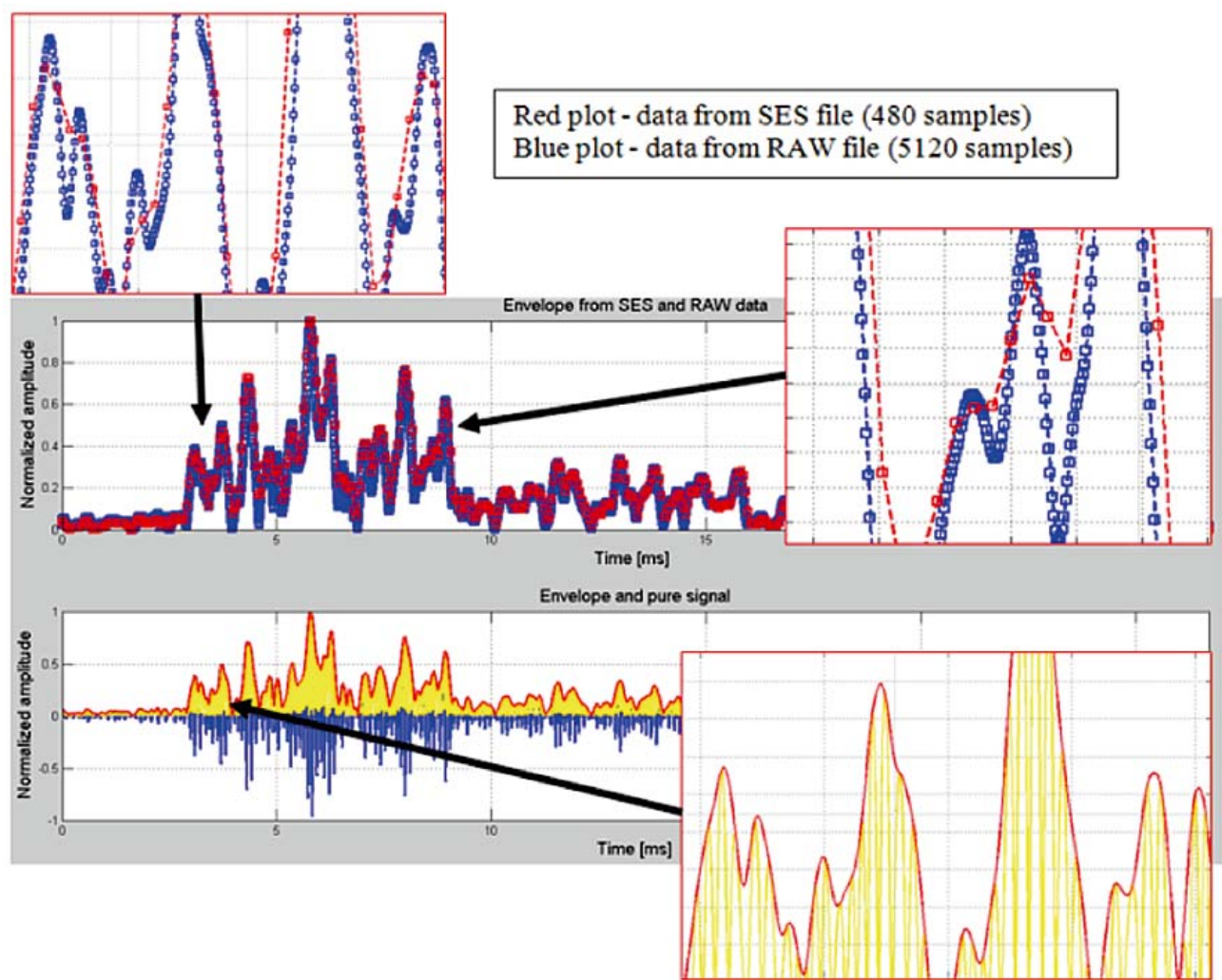

Fig. 9. Comparison of *.SES and *.RAW data 
The interesting comparison of the data was expanded in the upper part of Fig. 9. Difference in their quality can be observed, which clearly shows that the slow sampling brings errors connected with resolution, causes losing information about e.g. rapid drops in envelope, that can be very important for searching the objects buried not deeply. The envelope calculated from the recorded pure echo signal is shown in the lower part of Fig. 9 - its expanded part shows all details without losing information. After using proper post-processing tools and *.raw data files small changes in signals can be observed during analyzing full echo runs.

\section{Filtering pure signal and data presentation on echogram}

The below described results are obtained from Matlab software where appropriate algorithms for data analyzing are implemented. Additionally, interesting results of sounding were selected to show rapid change in sediment properties. The first $370 \mathrm{~m}$ recorded on echogram show the sea bottom located in depth of $54 \mathrm{~m}$ and sediment layers up to $85 \mathrm{~m}$. After sounding $380 \mathrm{~m}$ distance we can observe fast change of penetration depth which decreases to $2.5 \mathrm{~m}$. Looking forward the nearest $1000 \mathrm{~m}$ of the visualized echogram one can observe a stronger echo reflected from the bottom and no information from the sub-bottom zone.

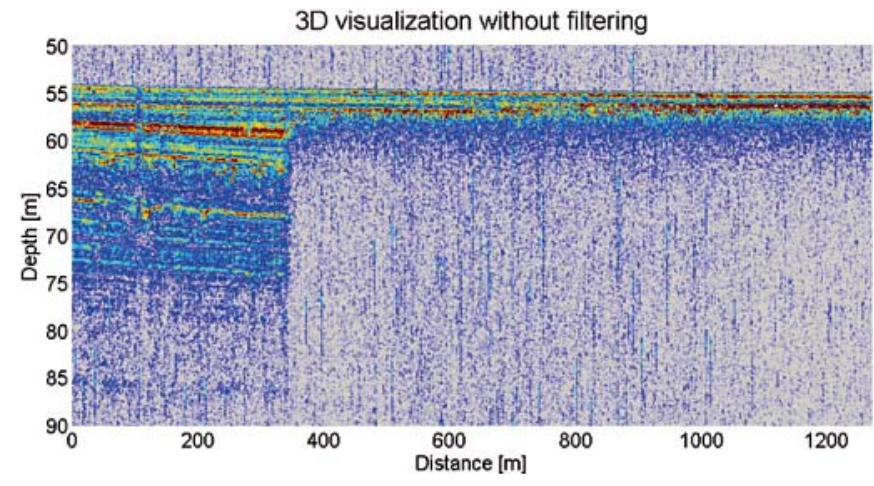

Fig. 10. Raw data displayed in the form of echogram - pure signal
Having known the sounding pulse and sampling frequency it was possible to filter signals by using the band-pass filter. The result of the filtering is shown in Fig. 11, where is possible to observe the clear echogram with more differentiated echo levels in the three marked zones.

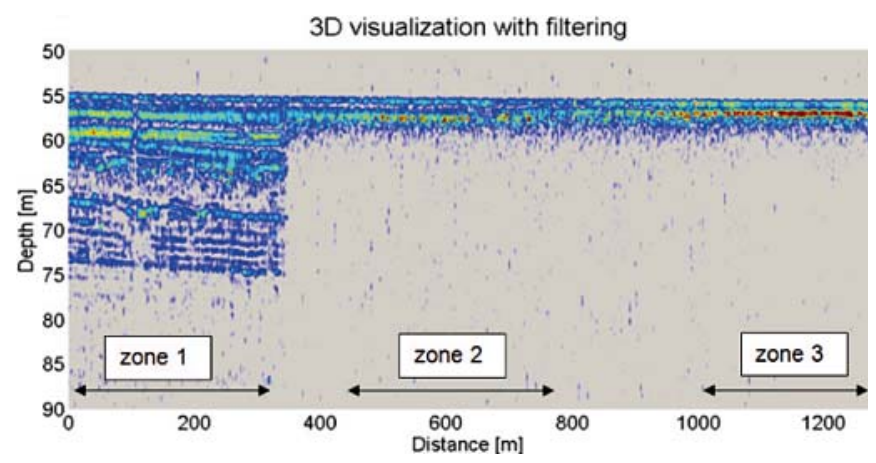

Fig. 11. Raw data displayed in the form of echogram - signal passed through band-pass filter

The time series of the reflected pulses received after transmitting sounding pulse were plotted on three charts (Fig. 12). The first one visualizes results from the sounding zone I. The analyzing of the signal did not give clear classification of echo reflected from layers - signals are continuous, but after forming the envelope characteristic hooks (which arise during impact of two overlapping reflected sounding pulses) allow to plot echograms with visible boundary between layers. The signal from the middle part of bottom sounding (zone II) exhibits echo from the first layer located on a higher level than in the zone I, that can be interpreted for instance as another type of bottom material imposed on a muddy bottom.

Looking at the third time series one can observe that in this case the first and second echo show much higher level than in the two first zones. To get proper interpretation of sounding results (especially in the third case - possible simulation of such layer arrangement) a correlation with the data received from trials on the $30 \mathrm{~m}$ water tank is necessary where differential sounding pulses were a.o. measured and the sounding of two

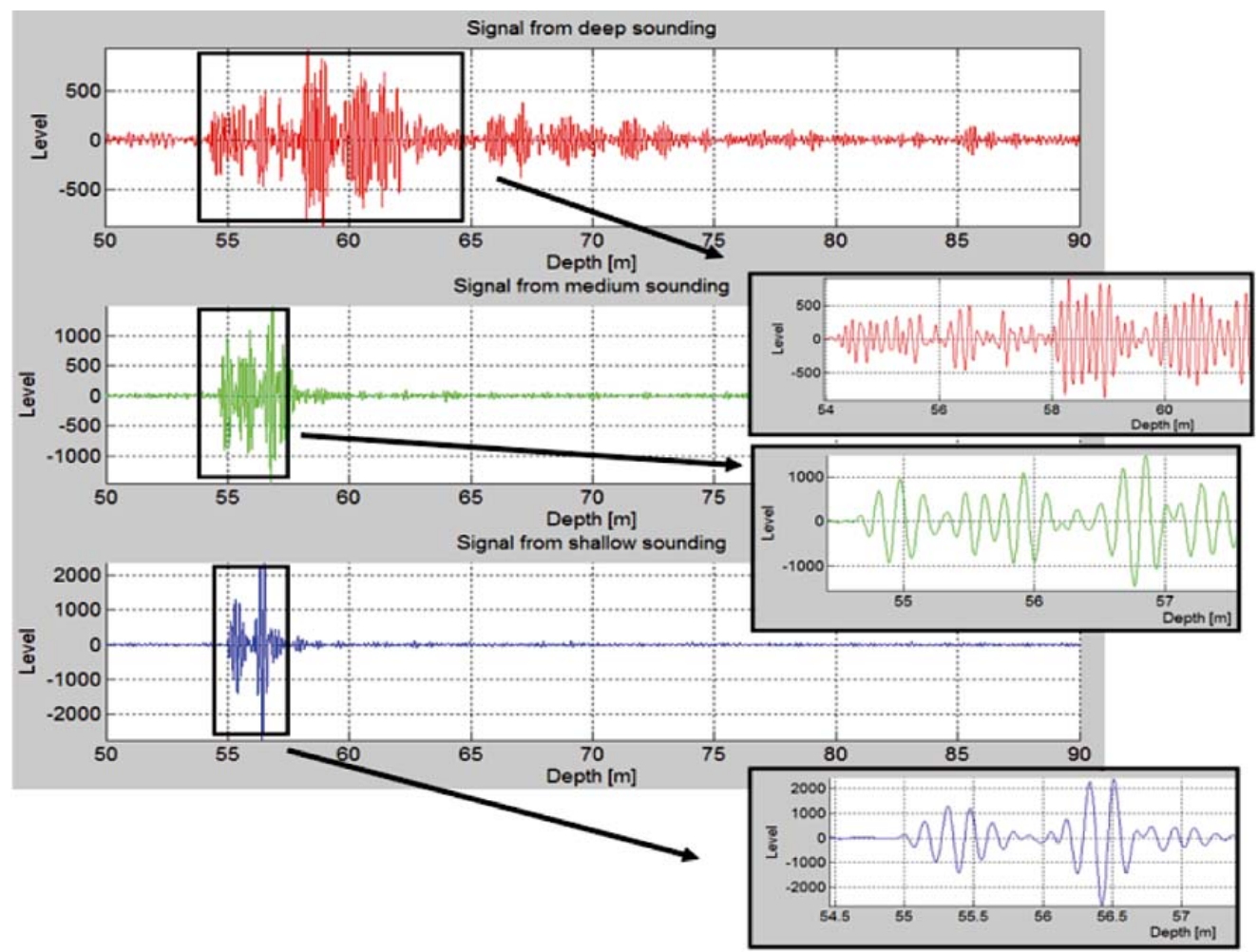

Fig. 12. Time series of raw signals 
layers side by side with different types of bottom sediments placed in special frames, was performed.

$4 \mathrm{kHz}$ sounding pulse is shown in Fig. 13. The sounding pulse is nearly the same as the reflected signal from zone III, that can be checked during analyzing Fig. 12. The first echo is a little fuzzy, that can be interpreted as reflection from a muddy/clay material but the second one corresponds directly to the transmitted signal.
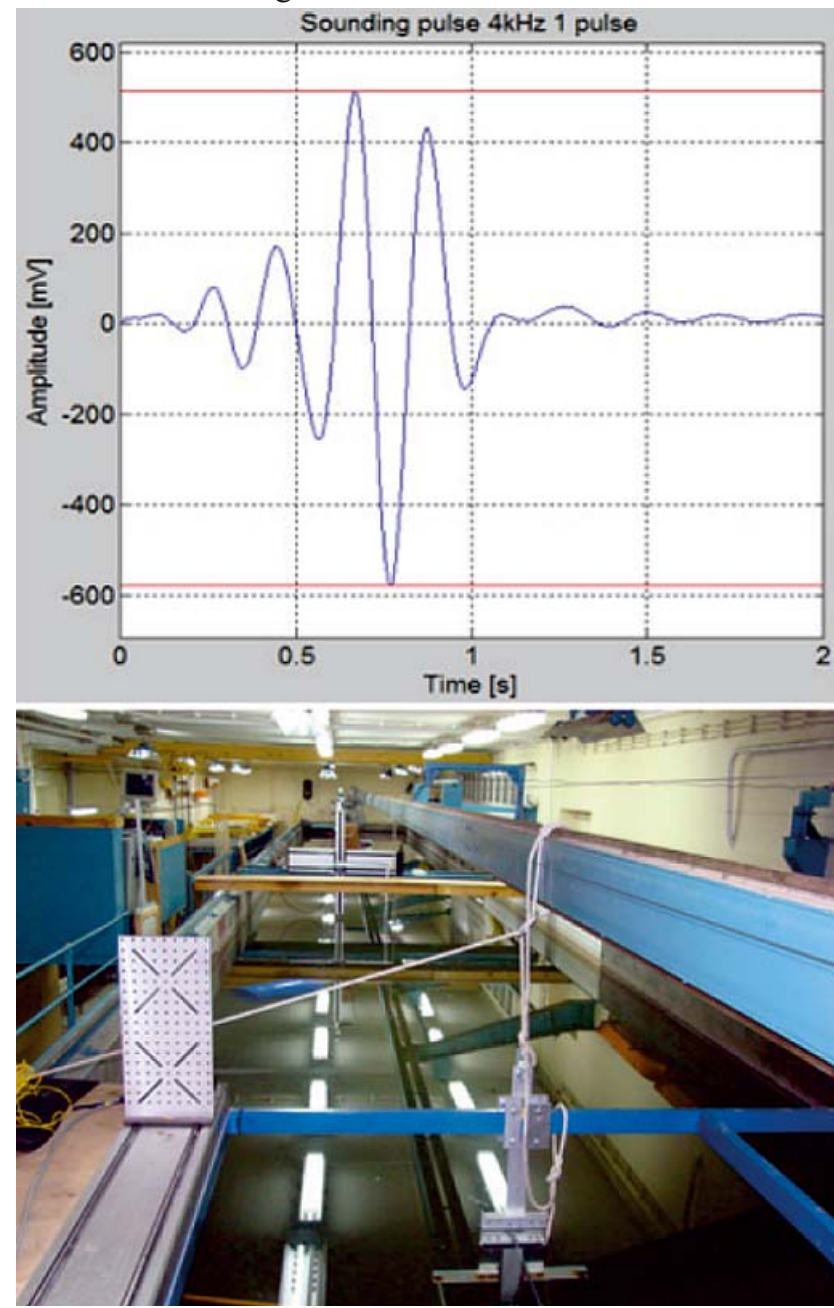

Fig. 13. Low-frequency pulse of $4 \mathrm{kHz}$ (upper figure) measured during the trials in the water tank (lower figure)

To compare echo power level, respective soundings from each zone, after filtration, were averaged and displayed in Fig. 14 in the form of artificial echogram.

$3 \mathrm{D}$ visualization arfter processing - with filter

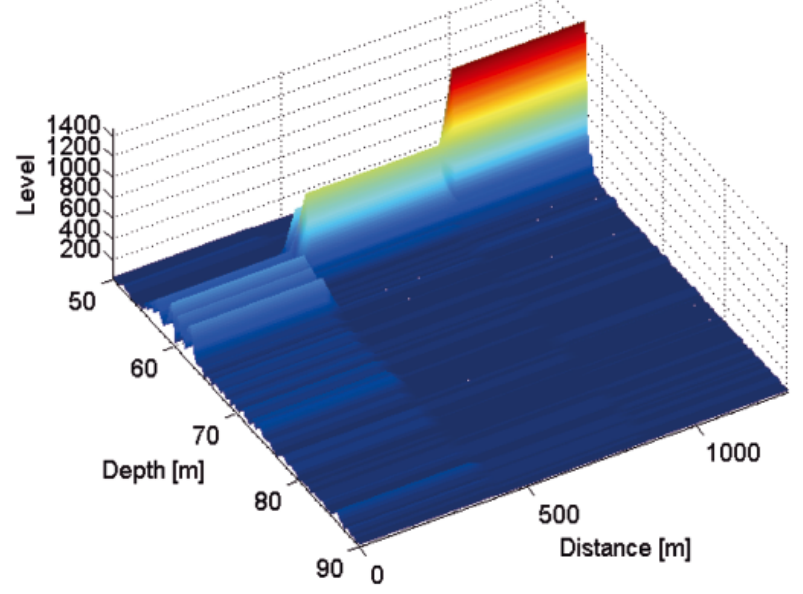

Fig. 14. Comparison of echo strength
The echogram confirms that the deepest bottom penetration has lower echo level along whole path. Strength of the signal reflected from the area near zone I is greater but not as great as the signal coming from zone III. During sea trials several points rapid change of sediment penetration depth were localized, that gives opportunity to mark the points on map and apportionment border on bay (red colour line) whose shape is regular and can confirm real natural properties of the sediments in this area.

The deepest penetration zone is marked yellow and the red area corresponds to place where investigation of sediments is reduced to that of the high power echo reflected from the first layer (the sediment samples, taken not from the whole coastal zone, were analyzed during water tank laboratory measurements, where they were placed in the frames to be sounded with low frequency pulses emitted by the same unit as during sea bottom trials).

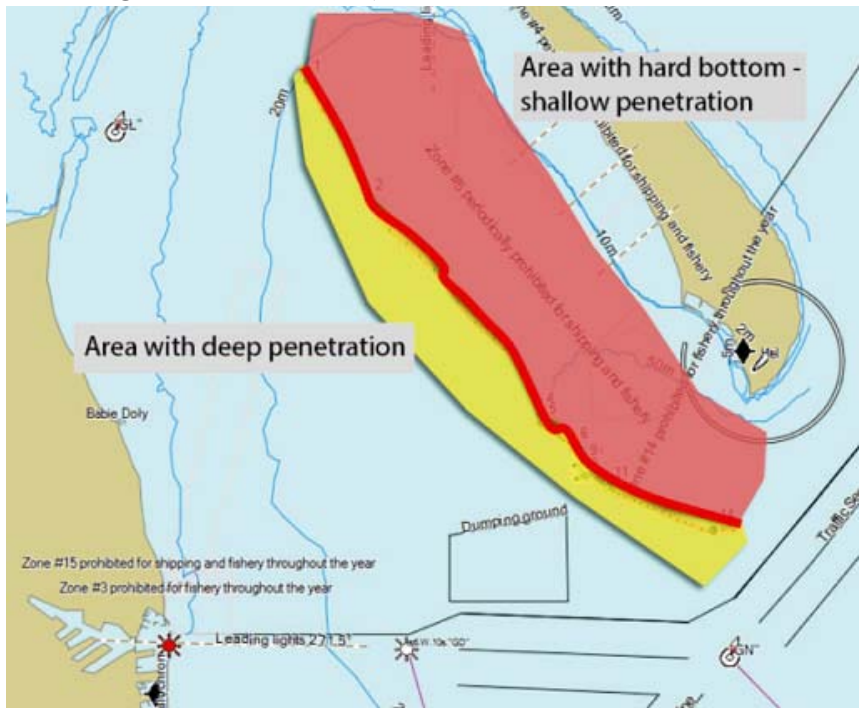

Fig. 15. Red line - border of penetration

After expanding an interesting fragment of the echogram (Fig. 16) it is possible to calculate a distance from which the penetration depth decreases from 20 to $5 \mathrm{~m}$. The distance is near $13 \mathrm{~m}$ which corresponds to a fast change in bottom properties. However such geological case can also appear under natural conditions and this change does not result from one sounding ping to another so it is not due to a change in sounding parameters, like e.g. frequency.

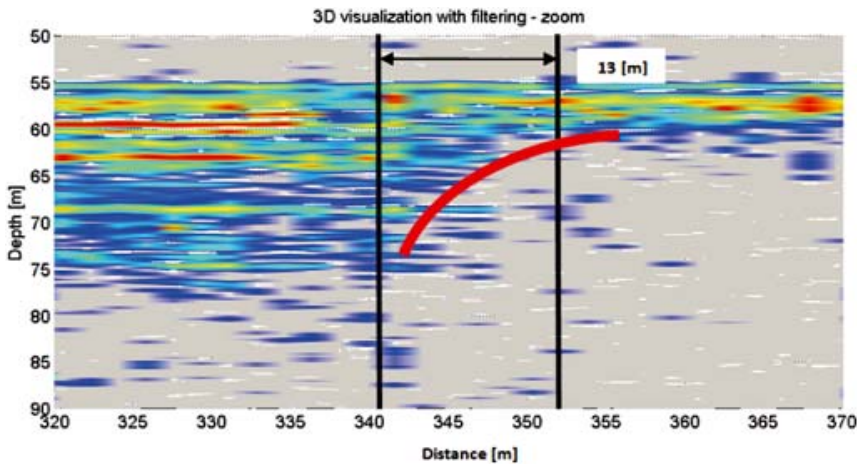

Fig. 16. Expansion of rapid change of penetration depth

The sounding results which show rapid change of penetration depth are correlated with results obtained by another researchers and published on relevant websites. The results obtained by these authors are equivalent to echograms produced by different echo-sounders, like e.g. the TOPAS 40 - results titled "Results from shallow gas area outside Namibia", published on Kongsberg website. 


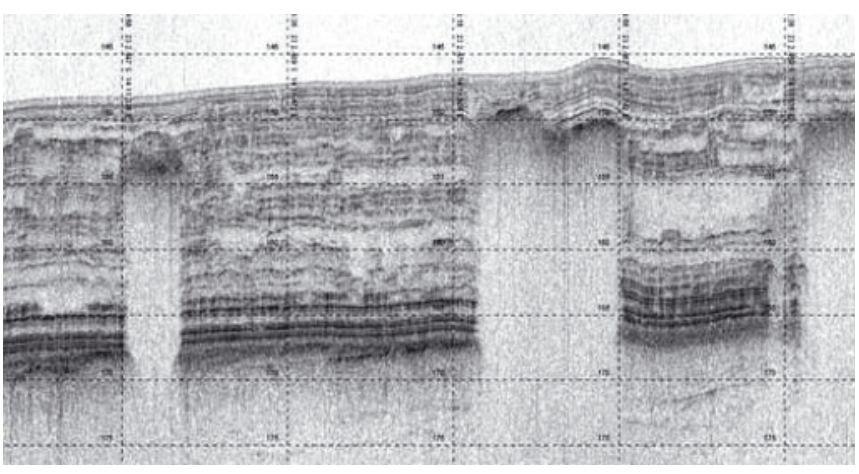

Fig. 17. Kongsberg's TOPAS 40 echogram

It is necessary to point out that during measurements a compensation of roll (beam stabilization) and heave motions was realized with the use of the MRU-Z device. But it is important to remember of influence of not compensated pitch motion, which depends on sea state and can be considerable. It is easy to confirm the influence during analyzing the echogram shown in Fig. 18 where bottom sediments are the same but pitch motion makes sounding pulses hitting bottom at different angles, that changes echo amplitude. These results were taken during high surge motion in order to get an example of such data. The typical sounding operation was realized during calm weather.

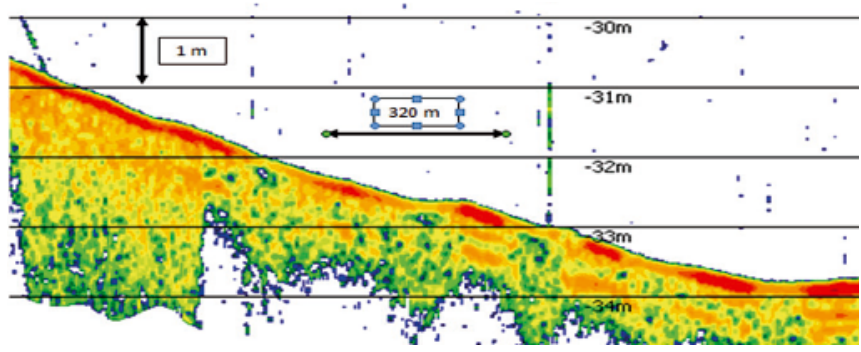

Fig. 18. Example of different levels of echo reflected from the same sediment

\section{METHODS OF POST-PROCESSING VISUALIZATION}

During searching for difference between sediment properties or checking a mud or silt layer covering sandy bottom it is important to set, in a proper way, threshold for minimum values to be visualized on echogram, in order to make substantial differences visible. Additionally, the algorithm which defines distribution of colours should be set to logarithmic or linear mode. By using the Matlab as programming software to visualize data, two examples taken during sounding two areas close to each other, are shown below.

Each echogram contains two parts - on the left side are visualized sounding results where penetration depth was up to $3 \mathrm{~m}$, and on the right side - echoes reflected from the layers located $15 \mathrm{~m}$ under the bottom. The colour scale was set to linear mode. In Fig. 19 the threshold was set to minimum to make all details visible, but usually it is difficult (especially in logarithmic colour scale mode) to distinguish a mud layer placed on hard bottom. The threshold level was set to the value which cuts off envelope picks resulting from low power echoes, shown in Fig. 20. It can be observed that the three thick layers which were first the bottom layer, now are covered with $3 \mathrm{~m}$ thick sediment. The same comparison can be seen in 3D view of envelopes, as shown in Fig. 21. The envelope used in the comparison is averaged from sounding records, that makes its peaks smooth. Additionally, when data include much noise it is possible to use a stacking algorithm (adding consecutive echo signals and receiving new, processed data) and smoothing function which decreases influence of noise on the results.

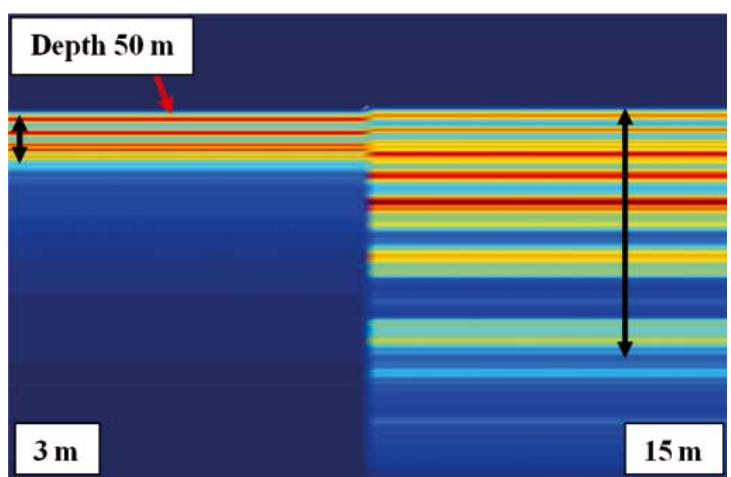

Fig. 19. Echogram with minimum threshold value

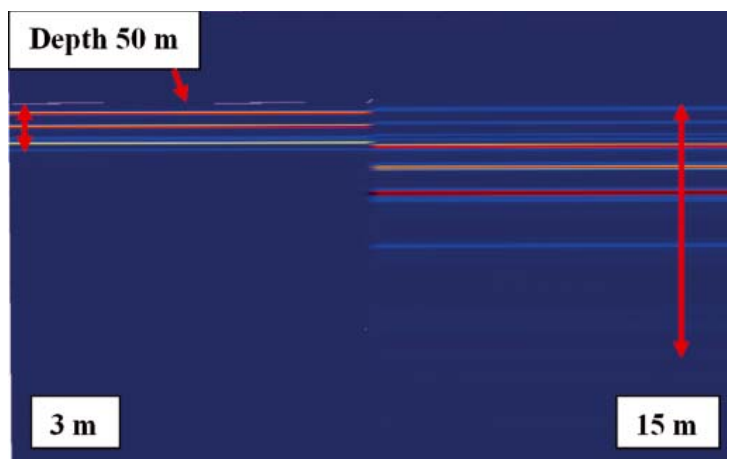

Fig. 20. Echogram with high threshold value

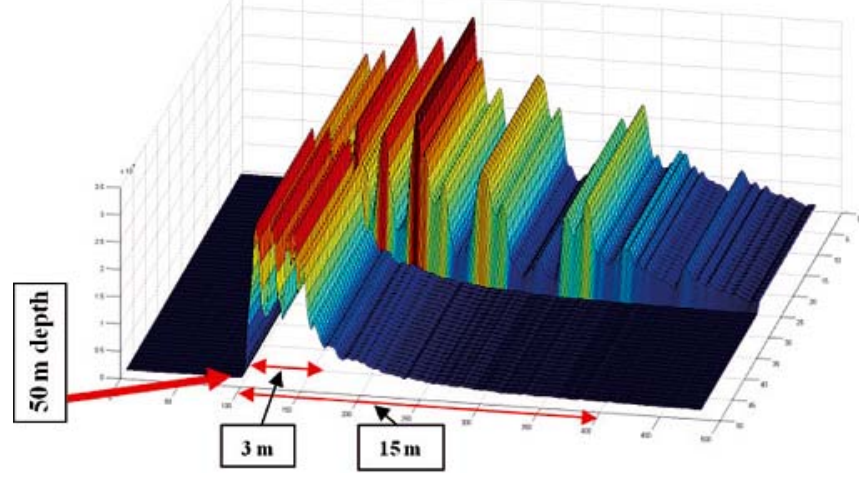

Fig. 21. 3D presentation of data by using Matlab software

Operator should select proper configuration of the software intended for co-operating with parametric echo-sounder, depending on the type of research to be performed, namely:

a) examination of sediments layers,

b) searching for a buried object.

Having known that the envelope contains constant number of samples, not depending on range, when searching for a small buried object located at constant depth on flat bottom, the start sampling range can be set $1 \div 2 \mathrm{~m}$ above the bottom and $5 \mathrm{~m}$ in its value, i.e. the smallest one. It will give the highest resolution which provides the sampling step of $0.01 \mathrm{~m}$, that makes it possible to observe small changes in reflected sounding pulse. When the main aim is to investigate the sediment layers up to $30 \mathrm{~m}$ below the bottom surface, operator should set up the start sampling range to be $4 \div 5 \mathrm{~m}$ above the bottom surface and the sounding range should be set to $35 \div 40 \mathrm{~m}$. The resulting resolution is not very high but satisfactory in the case in question.

If something interesting is noticed in the seabed structure, for example at $10 \mathrm{~m}$ depth below the bottom surface, the sounding should be repeated with the sampling window set up in the way described in the searching for buried object but with the start sampling range value adjusted to actual situation (it could be set below bottom surface). 
The sounding results obtained from the software intended for imaging data in real time are presented in Fig. 22 and 23, and the results post-processed with the use of the software dedicated to this type of data - in Fig. 24 and 25. In the considered case the bottom is located $46 \div 48 \mathrm{~m}$ below sea surface and the penetration range reaches $27 \mathrm{~m}$ in the maximum point.

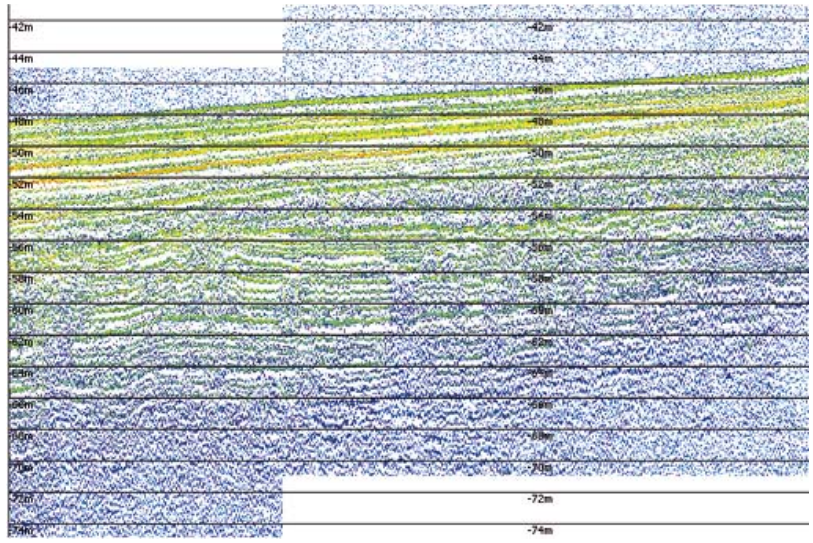

Fig. 22. Envelope from 480 samples - $6 \mathrm{kHz} 2 \mathrm{p}$ (from SES data - differential view)

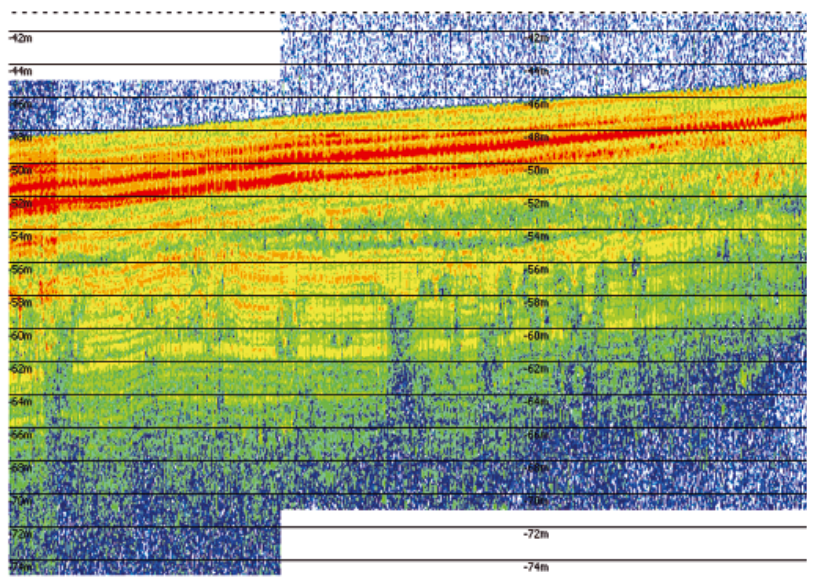

Fig. 23. Envelope from 480 samples - $6 \mathrm{kHz} 2 \mathrm{p}$ (from SES data - full envelope view)

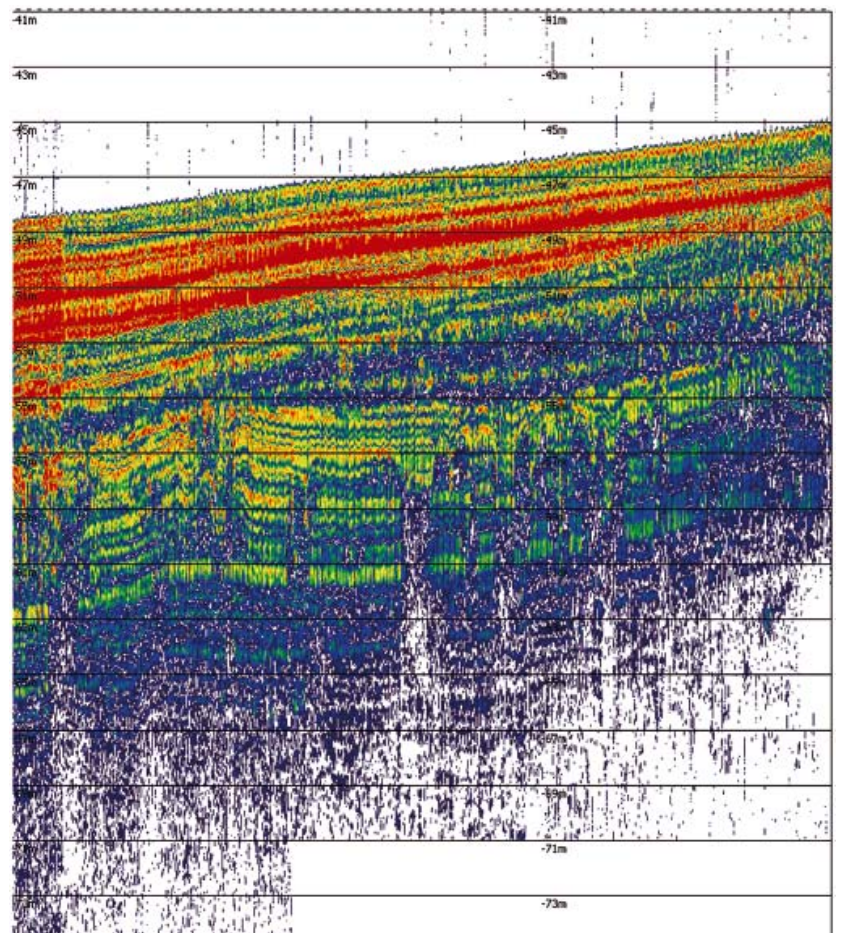

Fig. 24. Envelope from 5120 samples $-6 \mathrm{kHz} 2 \mathrm{p}$ ( $R A W$ data - envelope with 15 colours)

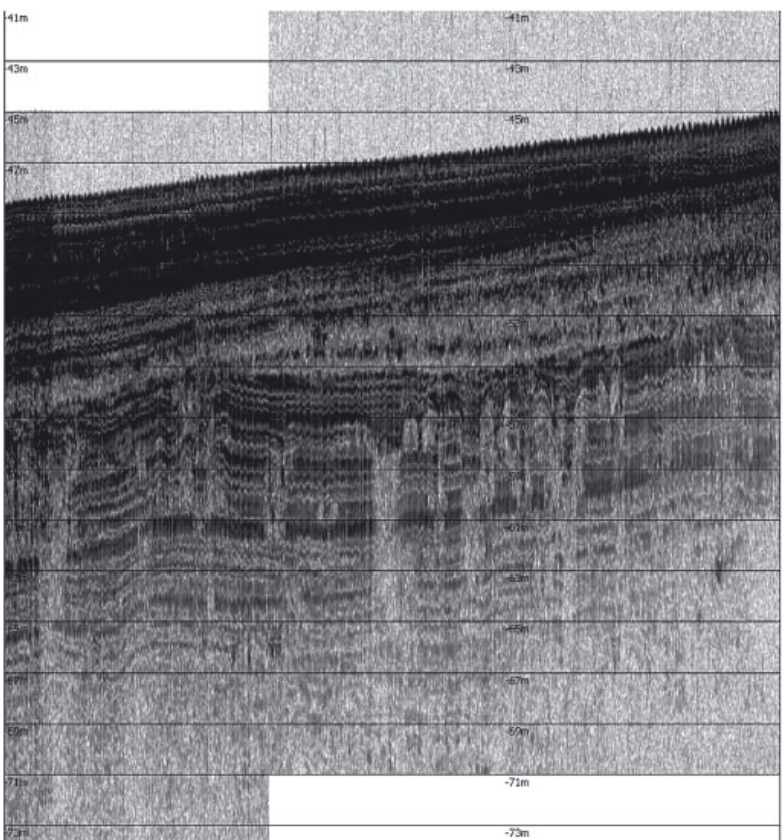

Fig. 25. Envelope from 5120 samples $-6 \mathrm{kHz} 2 p$ ( $R A W$ data - envelope with 30 gray-scale colours)

The software dedicated to the sub-bottom profiler offers various configurations. Most important is to set up frequencies of differential sounding pulses, which can be chosen in the range of $4 \mathrm{kHz} \div 15 \mathrm{kHz}$. The primary frequencies are set up near $100 \mathrm{kHz}$, depending on a differential sounding pulse. During work with geological aspects where it is important to investigate structure of sediments, the lowest frequency is required, that can be checked on the below presented echograms (where high differences were used for visualization of the same sounded bottom). When a new research area is examined it is useful to apply multi-frequency option. It allows to sound with the use of three different sounding pulses one by one. An example of such research is illustrated in Fig. 12, 13 and 14. The results are elaborated in the logarithmic scale of colours and the TVG software set to $0.6 \mathrm{~dB} / \mathrm{m}$.

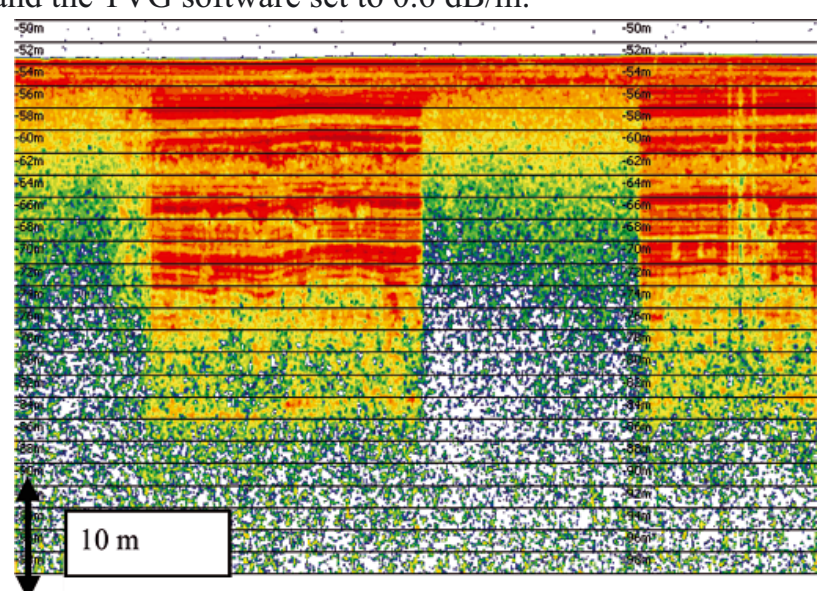

Fig. 26. $5 \mathrm{kHz}$ frequency of echosounder souding pulse

By using data processing algorithms and Matlab software to compare and analyze data which contain information about buried objects, is possible. There are many possibilities to illustrate processed data in 2D, 3D, horizontal and vertical view. Having geographical position linked with sounding data it is possible to visualize different models of searched objects. Below an example of visualization and measurement of three buried targets is shown. Additionally, application of scale of colours, where user can define step, threshold, maximum and minimum values, provides a wide range of visualization capabilities. 


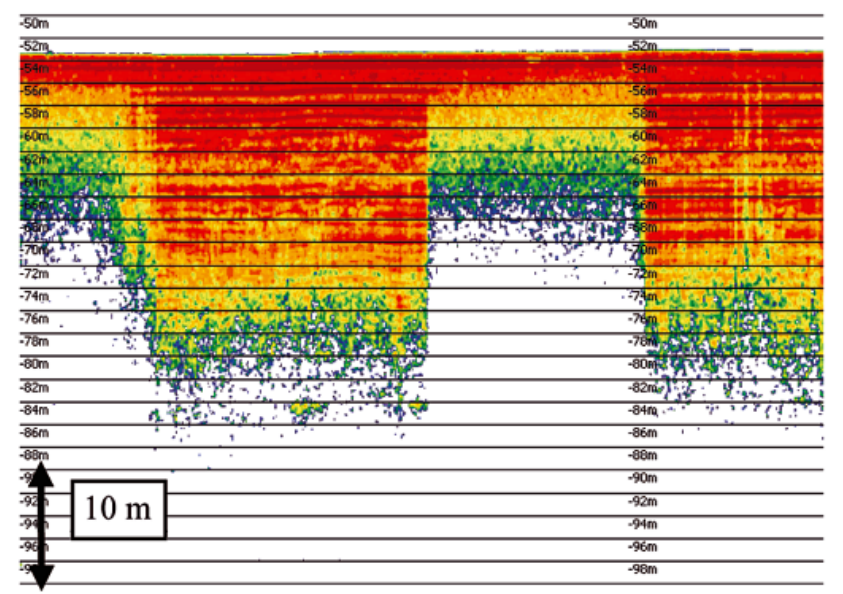

Fig. 27. $8 \mathrm{kHz}$ Frequency of echosounder souding pulse

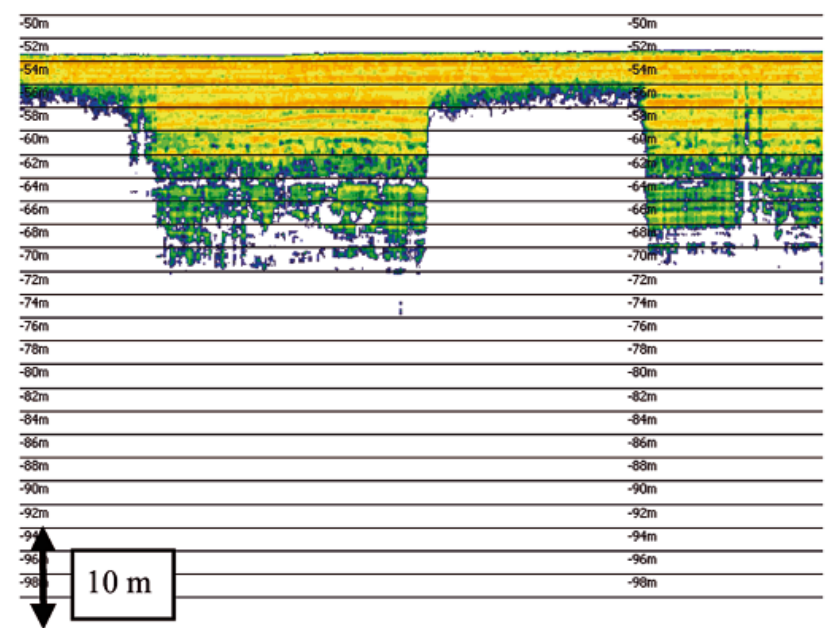

Fig. 28. $12 \mathrm{kHz}$ Frequency of echosounder souding pulse
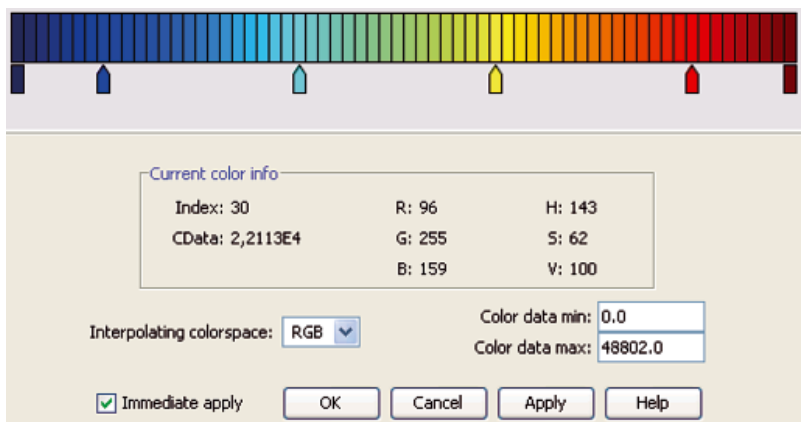

Fig. 29. Scale of colours of echosounder souding pulse

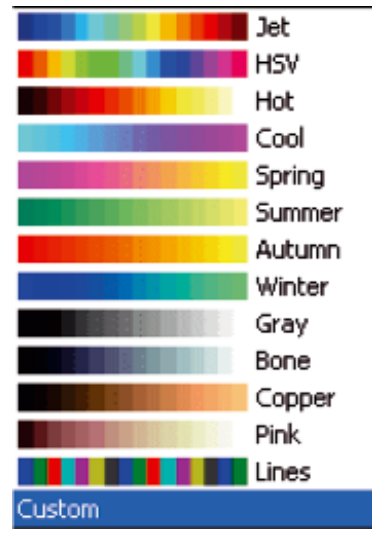

Fig. 30. Set of default colours used in the Matlab

\section{SUMMARY}

During the post-processing of data different algorithms should be applied depending on a type of research (examination of sediment layers or searching for buried objects). The data

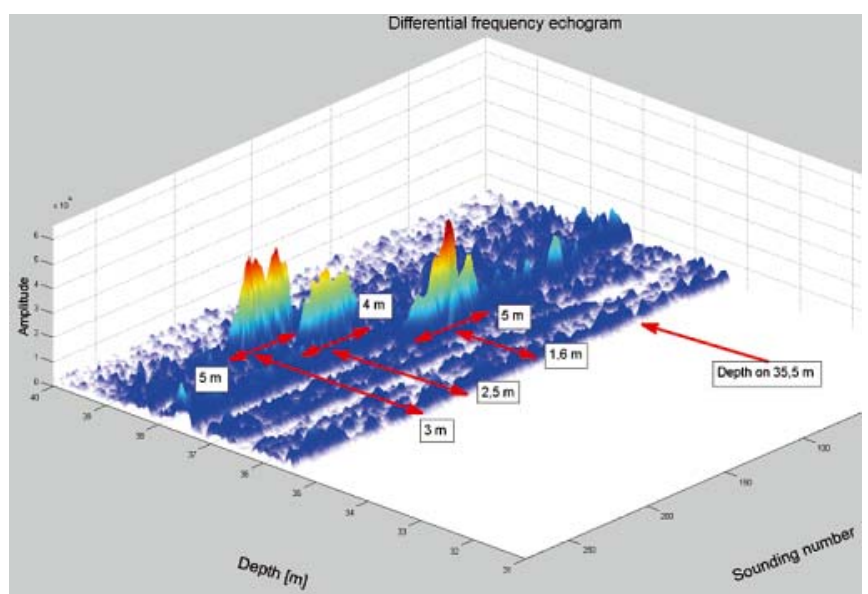

Fig. 31. Three buried objects - imaged by using the Matlab

analyzing should additionally improve operator's knowledge useful for new trials, as to the describing of proper configuration of a software intended for cooperating with parametric echosounder, frequency and length (number of cycles) of pulses to be set depending on currently received results. Methods of data processing in real time and raw data post-processing provide many possibilities. It is necessary to have at one's disposal an algorithm which describes a proper way of effective work with the data, even during trials.

\section{Acknowledgments}

The research presented in this paper has been partly conducted in the framework of the projects No. O ROB 000701.

\section{BIBLIOGRAPHY}

1. G. Grelowska, E. Kozaczka: Nonlinear properties of water (in Polish), AMW, Gdynia, 1996

2. K. Naugolnykh, L. Ostrovsky: Nonlinear Wave Processes in Acoustics, Cambridge University, Cambridge, 1998

3. P. Blondel, A. Caiti: Buried Waste in the Seabed Acoustic Imaging and Bio-Toxicity, University of Bath, UK, 2007

4. Innomar Technologie GmbH: SES-2000 Narrow-beam parametric sub-bottom profilers, Innomar Technologie, Rostock, 2008

5. E. Kozaczka, G. Grelowska, S. Kozaczka: Images of the seabed of the Gulf of Gdansk obtain by means of the parametric sonar, Acta Physica Polonica A, Vol. 118, No 1, 91-94, 2010.

6. G. Grelowska, E. Kozaczka: Sounding of layered marine bottom - modelling investigations, Acta Physica Polonica A, Vol. 118, No 1, 66-70, 2010.

7. G. Grelowska, E. Kozaczka, S. Kozaczka, W. Szymczak: Sea bottom structure investigation by means of acoustic methods, Polish Journal of Environmental Studies, Vol. 19, No 4A, 35-38, 2010.

8. G. Grelowska, E. Kozaczka, S. Kozaczka, W. Szymczak: Post processing and selecting data obtain with parametric subbottom profiler SES-2000 Standard during sounding the Gulf of Gdansk, 11th European Conference on Underwater Acoustics 2012 - ECUA 2012, Volume 34 Pt. 3, p. 1446-1453, Edinburgh United Kingdom, 2-6 July 2012.

9. Results from shallow gas area outside Namibia: http:// www.km.kongsberg.com/ks/web/nokbg0240.nsf/AllWeb/ 56E492C388344357C1256F800045E141?OpenDocumen

\section{CONTACT WITH THE AUTHORS}

Eugeniusz Kozaczka, Prof., kozaczka@pg.gda.pl Grażyna Grelowska, Prof., ggrel@wp.pl Sławomir Kozaczka, M.Sc., milites@vp.pl Wojciech Szymczak, M.Sc., ws2@o2.p1

Polish Naval Academy

Śmidowicza 69

81-103 Gdynia POLAND 